The International Journal of Engineering and Science (IJES)

|| Volume || 6 || Issue || 6 || Pages || PP 01-15|| 2017 ||

ISSN (e): 2319 - 1813 ISSN (p): $2319-1805$

\title{
Experimental Study on Gypsum as Binding Material and Its Properties
}

\author{
Arun ReddyThumma \\ Department of Civil Engineering, Warangal Institute of Technology and Sciences, \\ Engineer, the Indian Hume Pipe Co. Ltd,
}

\begin{abstract}
Cement is widely noted to be most expensive binding material. The entire construction industry is in search of suitable and effective waste product that would considerably minimize the use of cements and ultimately reduces the construction cost. Gypsum which has the pozzolonic properties is a way forward. The possibility of using Gypsum as a construction material need to be investigated. Two types of Gypsum namely Natural Gypsum (NG) and Flue-Gas Gypsum (FGG) are commonly used in construction industry. A comparative study on effects of concrete properties when Gypsum is partially mixed with Lime and Fly ash is discussed. The compressive strength of concrete will be mainly studied. The study suggests that Gypsum has the potential to be used as replacement for cement, having good compressive strength performance. In Gypsum concrete different types of binding materials are rationally combined to produce a cementations composite that drives benefits other than cement concrete mixture. In this project, Gypsum, Lime and Fly ash will be used in proportions as concrete mixture and then fibers will be added together to form a Gypsum concrete. The present investigation is aimed to study the strength characteristics by casting and testing the specimens for 28 days. The compressive strength and splitting tensile strength of sample to be investigated individually by varying the percentage of Gypsum (80\%, 70\%, 60\%), Lime (10\%, 20\%, 30\%) and Fly ash (10\%, 20\%).

Keywords: Gypsum, Fly ash, Lime, Phospogypsum, Binding material, Gypsum concrete, Replacement to Cement, Water-binder ratio, Compressive strength, Tensile strength, Flexural strength, Waste, Sustainability, Setting time, Environment
\end{abstract}

ABSTRACT

Date of Submission: 12 May 2017

Date of Accepted: 03 June 2017

\section{1: GENERAL}

\section{INTRODUCTION}

Gypsum is one of the natural wastes evolved from the industries and leads to environmental pollution. As Gypsum has proved itself as a pozzolonic material it is used for replacement of cement in the concrete mix. The use of by-products is an environmental friendly method of disposal of large quantities of materials that would otherwise pollute land, water and air.The emission of carbon-dioxide into the environment can be reduced by reducing the use of ordinary Portland cement. Due to growing environment concerns and need to conserve energy and resources, efforts have been made to utilize the waste material of industrial and agro products in the construction industry as a pozzolonic mineral admixture to replace ordinary Portland cement. By considering all the above conditions, Gypsum which is a pozzolonic material is used for replacement of cement which reduces the percentage of cement in the concrete mix globally. The Gypsum concrete is made of fine aggregates, coarse aggregates, lime, flyash and gypsum. It is an eco-friendly product which controls the environmental pollution, reduces the cost of concrete and gives high strength concrete for construction.

\section{2: Introduction Of Materials}

\subsection{1: Gypsum}

Gypsum is a soft sulphate mineral composed of calcium sulphatedihydrate, with the chemical formula $\mathrm{CaSo}_{4} \cdot 2 \cdot \mathrm{H}_{2} \mathrm{O}$. Gypsum contains calcium, sulfur bound to oxygen and water. Gypsum is an abundant mineral and takes different forms. This mineral can be helpful to humans, animals, plant life and the environment.

Two types of Gypsum is present which are classified as 


\subsubsection{1: Natural Gypsum}

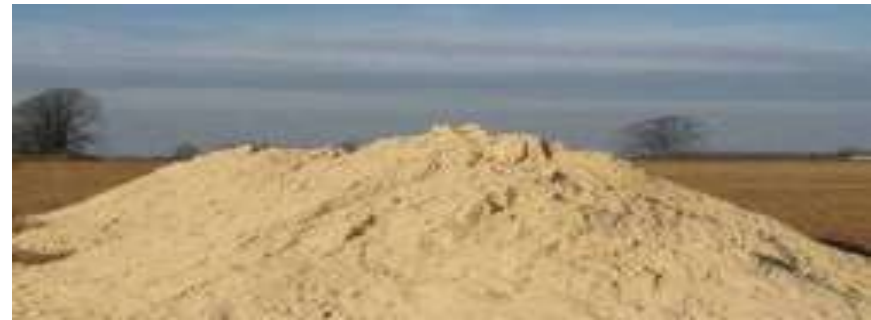

Fig 1: Gypsum

Natural Gypsum occurs in sedimentary rock formations. Gypsum rock is mined or quarried, crushed and ground into a fine powder. In a process called calcining, the powder is heating to approximately 350 degrees F, driving off three fourths of the chemically combined water. The calcined gypsum becomes base for gypsum plaster, gypsum board and other.

Used for

- As a soil addictive to improve the soils workability and receptivity to moisture, and to overcome the corrosive effect of alkalinity.

- As an additive in turbid water, particularly ponds, to settle dirt and clay particles without injuring aquatic life.

- To create surgical and orthopedic casts.

- As a food addictive.

- As a color addictive for drugs and cosmetics.

- A primary ingredient in toothpaste.

\subsubsection{2: Flue-Gas Desulfurization OrSynthetic Gypsum}

Flue-Gas Desulfurization is a byproduct of desulfurization of flue gas from the stacks of fossil fueled power plants, emissions captured from smoke stacks can be purified into a hard substance and manufactured into gypsum. Some type of FGD gypsum is generally considered unsuitable for use due to potential environmental hazards. Synthetic gypsum with potentially harmful material is not used to manufacture gypsum board.

Used synthetic gypsum

- Industry contributes to a cleaner environment.

- To keep the air clean

\begin{tabular}{|l|l|}
\hline Chemical classification & Sulphate \\
\hline Colour & Clear, colourless, white, gray, yellow, red, brown \\
\hline Streak & White \\
\hline Luster & Vitreous, silky, sugary \\
\hline Diaphaneity & Transparent to translucent \\
\hline Cleavage & Perfect \\
\hline Mohs hardness & 2 \\
\hline Specific Gravity & 2.3 \\
\hline Diagnostic Properties & Cleavage, specific gravity, low hardness \\
\hline Chemical composition & Hydrous calcium sulphate, $\mathrm{CaSO}_{4} .2 . \mathrm{H}_{2} \mathrm{O}$ \\
\hline Crystal system & Monoclinic \\
\hline
\end{tabular}

Table 1: physical properties of gypsum

\subsection{2: Lime}

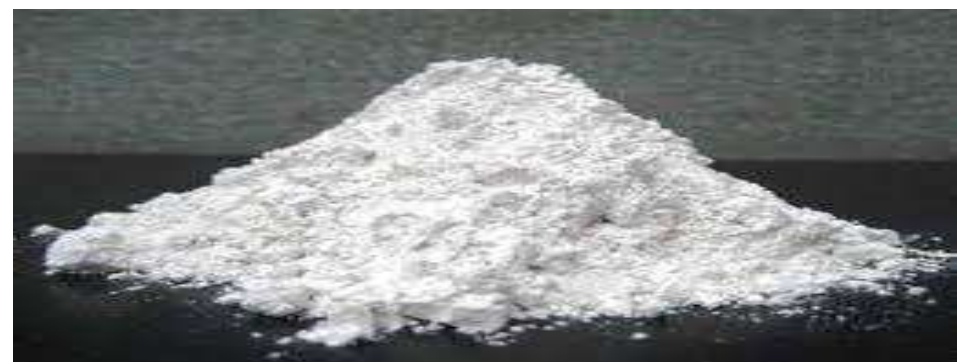

Fig 2: Lime

Lime is calcium containing inorganic material in which carbonates, oxides and hydroxides predominate. It is natural mineral which occurs as a product of coal seam fires and in altered limestone xenoliths in volcanic ejected. It originates with the use as building material and properties of sticking or adhering. The 
rocks and minerals are derived, typically limestone are composed primarily of calcium carbonate. They may be cut, crushed or pulverized and chemically altered. "Burning" (calcinations) converts them into the highly caustic material "quicklime" (calcium oxide, $\mathrm{CaO}$ ) and, through subsequent addition of water, into the less caustic (but still strongly alkaline) "slaked lime" or "hydrated lime" the process of which is called "slacking of lime"Limestone is the rock that contains $80 \%$ or more of calcium or magnesium carboates, including marble, chalk and marl. Limestone is extracted from quarries or mines. Part of the extracted stone, selected according to its chemical composition and granulometry, is calcinated at about $1000^{\circ} \mathrm{C}$ in different types of lime kilns to produce quicklime

$$
\mathrm{CaCo}_{3}+\text { heat } \rightarrow \mathrm{CaO}+\mathrm{Co}_{2}
$$

Before use, quicklime is hydrated, that is combined with water called slaking, so hydrated lime is also known as slaking lime is produced

$$
\mathrm{CaO}+\mathrm{H}_{2} \mathrm{O} \rightarrow \mathrm{Ca}(\mathrm{OH})_{2}
$$

"Dry slaking", is when quicklime is slaked with just enough water to hydrate the quicklime, but remain as a powder and is referred to as hydrated lime. In "wet slaking", enough water, but not too much, is added to hydrate the quicklime to a form referred to as lime putty.Because lime has an adhesive property with bricks and stones, it is often used as binding material in masonry works. It is also used in whitewashing as wall coat to adhere the white wash onto the wall.

\begin{tabular}{|l|l|}
\hline Hardness & 3 to 4 on mohrs scale \\
\hline Density & 2.5 to $2.7 \mathrm{~kg} / \mathrm{cm}^{3}$ \\
\hline Compressive Strength & $60-170 \mathrm{~N} / \mathrm{mm}^{2}$ \\
\hline Water Absorption & Less than $1 \%$ \\
\hline Porosity & Quite low \\
\hline Weather impact & Resistant \\
\hline
\end{tabular}

Table 2: physical properties of lime

\subsection{3: Fly Ash}

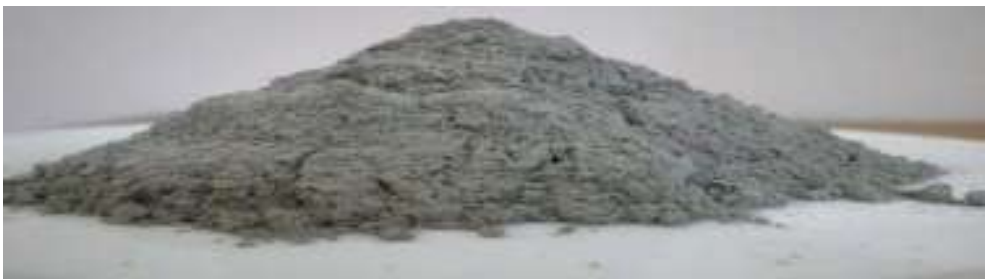

Fig 3: Fly Ash

Fly ash is also known as "pulverized fuel ash" is one of the coal combustion products and is composed of the fine particles that are driven out of the boiler with the flue gases. Fly ash is captured by electrostatic precipitators or particle separator equipment before the flue gases reach the chimneys of coal fired power plants. Depending upon the source and makeup of the coal being burned but all fly ash includes substantial amounts of silicon dioxide $\left(\mathrm{SiO}_{2}\right)$, aluminum oxide $\left(\mathrm{Al}_{2} \mathrm{O}_{3}\right)$ and calcium oxide $(\mathrm{CaO})$, the main mineral compounds in coalbearing rock strata.Coal Fly Ash is classified as hazardous waste under Resource Conservation and Recovery Act (RCRA).Two classes of Fly Ash are defined by ASTM C618:

\subsubsection{1: Class F Fly Ash}

The burning of harder, older anthracite and bituminous coal typically produces Class F fly ash. This fly ash is pozzulonic in nature, contains less than $7 \%$ lime $(\mathrm{CaO})$. Possessing pozzulonic properties, the glassy silica and alumina of Class F fly ash requires a cementing agent, such as lime or cement mixed with water to react and produce cementations compounds. Alternatively, adding a chemical activator such as sodium silicate can form a geopolymer.

\subsubsection{2: Class C Fly Ash}

Fly ash produced from the burning of younger lignite or sub bituminous coal, in addition to having pozzulonic properties, also has some self-cementing properties. In absence of water, Class $\mathrm{C}$ fly ash hardens and gets stronger over time. Class $\mathrm{C}$ fly ash generally contains more than $20 \%$ lime (Cao). Alkali and sulfate content are generally higher in class $\mathrm{C}$ fly ash. 


\subsection{4: Fine Aggregte}

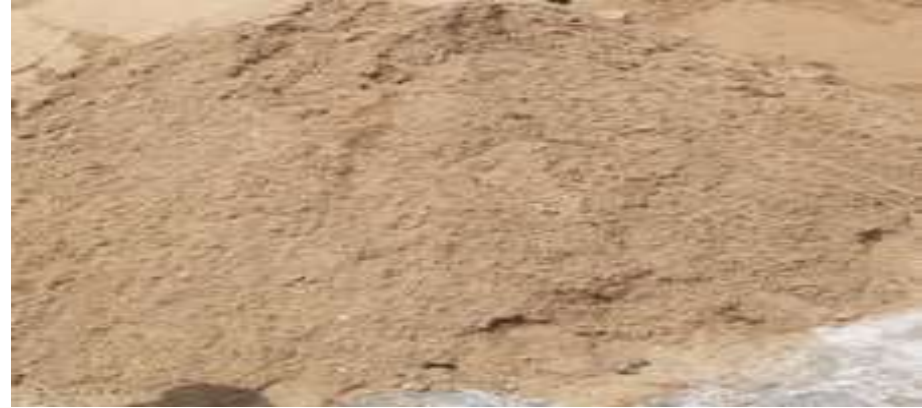

Fig 4: Fine Aggregate

i. Aggregate most of which passes through $4.75 \mathrm{~mm}$ IS sieve is used as fine aggregate.

ii. Natural Sand - Fine aggregate resulting from the natural disintegrating of rock and which has been deposited by streams or glacial agencies.

iii. Crushed Stone Sand - Fine aggregate produced by crushing hard stone.

iv. Crushed Gravel Sand - Fine aggregate produced by crushing natural gravel.

\subsection{5: Course Aggregate}

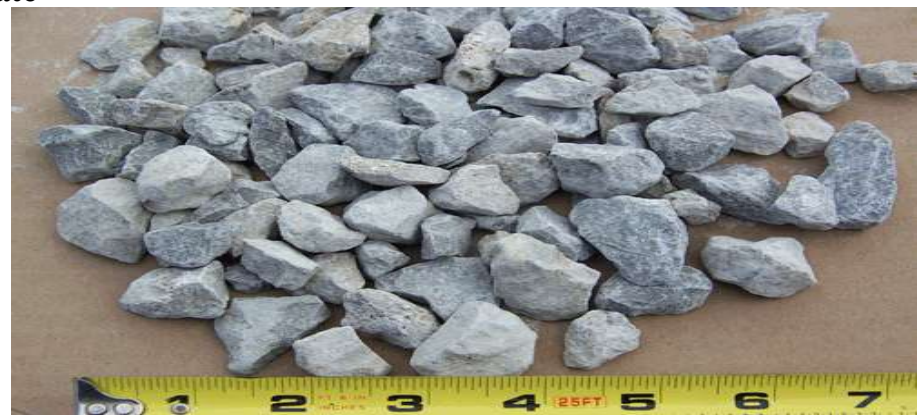

Fig 5: Coarse Aggregate

i. Aggregate most of which is retained on $4.75 \mathrm{~mm}$ IS sieve is used as coarse aggregate

ii. It is the uncrushed gravel or stone which results from natural disintegration of rock.

\subsection{6: Fibres}

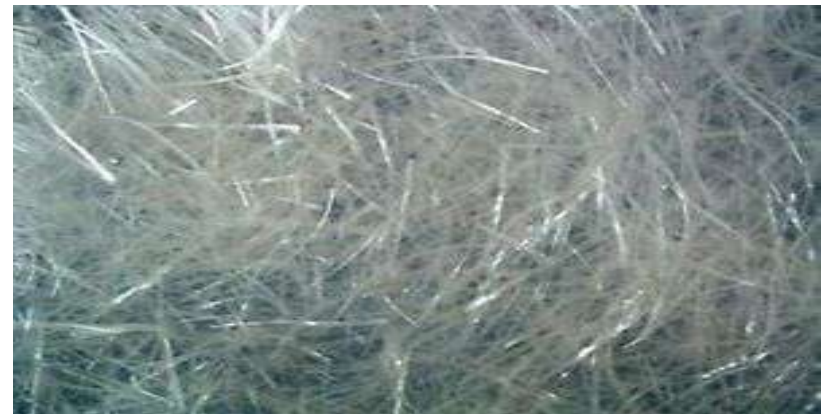

Fig 6: Glass fiber

Fiber material increases its structural integrity; these are uniformly distributed and randomly oriented. Fibers included in this project are glass fiber, natural fiber, polypropylene, synthetic fires - each of which lend varying properties to the concrete. In addition, properties changes with fiber material, geometries, distribution, orientation and densities.

Fibers can

a) Improve mix cohesion, improving pumpability over long distances.

b) Improve freeze thaw resistance.

c) Improve resistance to explosive spalling in case of a severe fire.

d) Improve impact resistance and abrasion resistance.

e) Increase resistance to plastic shrinkage during curing.

f) Improve structural strength. 
g) Reduce steel reinforcement requirements.

h) Reduce crack widths and control the crack width tightly, thus improving durability.

\section{AIM AND OBJECTIVES}

Aim of the project is to identify a new binding material which has the properties identical to that of ordinary portland cement, evaluate the strength potential of Gypsum with Fly Ash and Lime along with Water

The aim has been achieved through covering the following specific objectives

The main objectives of the project is to

$>$ Investigating the engineering properties and characteristics of samples collected.

$>$ Investigating the strength gain of composite material aspects.

$>$ Establishment of better suitable combinations of Gypsum, Fly Ash and lime compositions for tensile and compressive test under laboratory scale/conditions

\section{EXPERIMENTAL ANALYSIS}

3.1: Physical Test on Materials

3.2.: Gypsum, Lime and Fly Ash Proportions

\begin{tabular}{|c|c|c|c|}
\hline PROPORTION NO. & GYPSUM & FLY ASH & LIME \\
\hline 1 & 80 & 10 & 10 \\
\hline 2 & 70 & 10 & 20 \\
\hline 3 & 60 & 10 & 30 \\
\hline 4 & 60 & 20 & 20 \\
\hline
\end{tabular}

Table 3: Gypsum, Fly Ash and Lime composition

\subsection{1: Fineness Modulus}

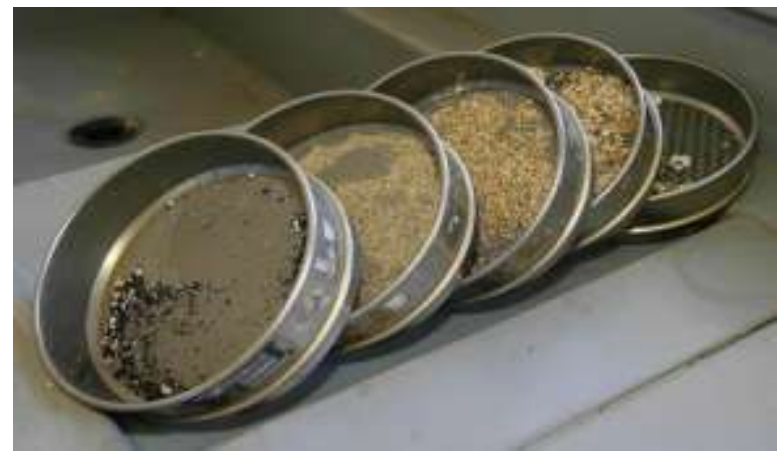

Fig 7: IS sieves

\section{Procedure:}

1. Weigh accurately $100 \mathrm{gm}$ of material and place it on a standard IS sieve 90 microns.

2. Breakdown any air set lumps in the sample with fingers but do not run on the sieve.

3. Continuously sieve the sample by holding the sieve in both hands and giving a gentle wrist motion or mechanical sieve shaker may be used for this purpose.

4. Weigh the residue left after 15 minutes sieving this residue shall not exceed the specified limits.

\subsection{2: Specific Gravity}

Procedure:

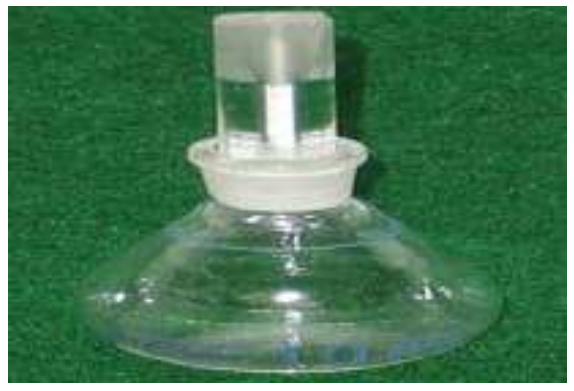

Fig 8: Specific Gravity Bottle

1. Clean dry and weigh specific gravity bottle.

2. Take certain quantity of material (about one fourth of the bottle) in the bottle and weigh $\left(\mathrm{w}_{2}\right)$. 
3. Pour kerosene over the material to fill the bottle and find the total weigh $\left(\mathrm{w}_{3}\right)$.

4. Clean the bottle thoroughly with kerosene and fill the bottle with kerosene and weigh $\left(\mathrm{w}_{4}\right)$.

5. Finally clean the bottle with water weighs $\left(\mathrm{w}_{5}\right)$.

\subsection{3: Standard Consistency}

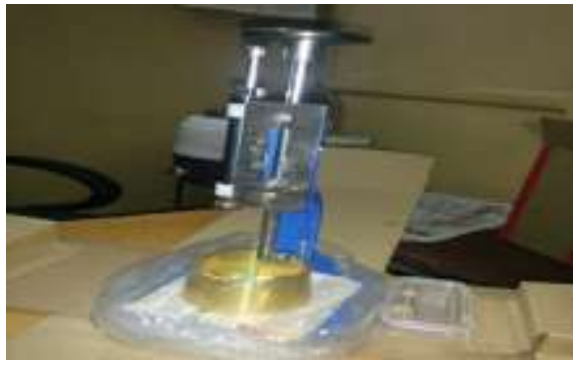

Fig 9:Vicat Apparatus

Procedure:

1. The mould and the non porous plate are washed, cleaned and dried.

2. Take $400 \mathrm{gm}$ of the given sample of cement is kept on the non porous plate

3. $30 \%$ water by weight of material is add very carefully to dry material and mixed thoroughly to get a neat material paste. Care should be taken that the time of gauging is not less than 3 minutes and not more than 5 minutes. The gauging time shall be counted from the time of adding water to the dry material until commencing to fill the mould.

4. The vicatmould is placed on the non porous plate and is filled with the prepared material paste with trowel, the surface is smoothened is level the mould.

5. By shaking mould slightly any air from the sample is expelled.

6. The non porous plate and mould are placed under the plunger.

7. The plunger is gently leveled to touch the surface of paste and then the indicator is adjusted to show zero reading.

8. The plunger is released quickly and allowed to penetrate in to the paste.

9. When the plunger comes to rest, the reading on the index scale is noted.

10. Several trails pastes are prepared with varying percentages of water and the test is conducted until the needle penetrated $5 \mathrm{~mm}-7 \mathrm{~mm}$ above the bottom of the mould.

\subsection{4: Setting Time}

Procedure:

1. Prepare a paste of $300 \mathrm{Gms}$ of material with 0.85 times the water required to a give a paste of standard consistency.

2. The time of gauging in any case shall not be less than 3 minutes not more than 5 minutes and the gauging shall be completed before any sign of settling occurs.

3. Count the time of gauging from the time of adding water to the dry cement until commencing to fill the mould.

4. Fill the vicatmould with this paste making it level with the top of the mould.

5. Slightly shake the mould to expel the air.

6. In filling the mould the operator hands and the blade the gauging trowel shall only be used.

a) Initial Setting Time

7. Immediately place the text block with the non porous resting plate, under the rod bearing the initial setting needle.

8. Lower the needle and quickly release allowing it to penetrate in to the mould.

9. In the beginning the needle will completely pierce the mould.

10. Repeat this procedure until the needle fails to pierce the mould for $5 \pm 0.5 \mathrm{~mm}$.

11. Record the period elapsed between the time of adding water to the cement to the time needle falls to pierce the mould by $5 \pm 0.5 \mathrm{~mm}$ as the initial setting time.

b) Final Setting Time

12. Replace the needle of the vicat apparatus by the needle with an angular ring.

13. Lower the needle and quickly release.

14. Repeat the process until the annular ring makes an impression on the mould.

15. Record the period elapsed between the time of adding water to the cement to the time when the annular ring fails to make the impression on the mould as the final setting time. 


\subsection{1: Specific Gravity}

\section{FINE AGGREGATE}

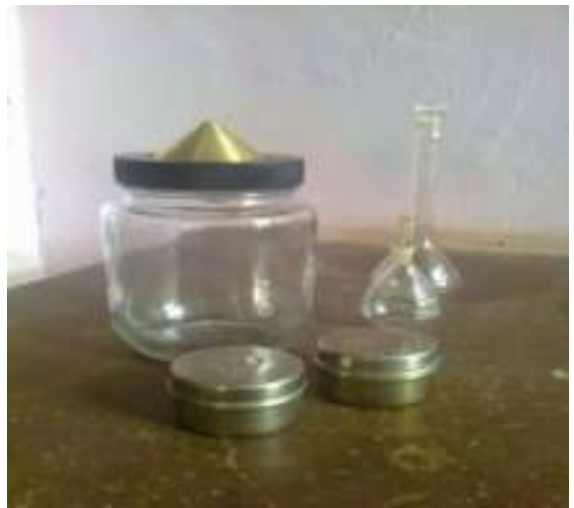

Fig 10: Pycnometer

Procedure:

1. Record the weight of the empty clean and dry pycnometer, $\mathrm{w}_{\mathrm{p}}$.

2. Place $10 \mathrm{gm}$ of a dry soil sample (passed through the sieve no.10) in the pycnometer. Record the weight of the pycnometer containing the dry soil, $\mathrm{w}_{\mathrm{ps}}$.

3. Add distilled water to fill about half to three-fourth of the pycnometer. Soak the sample for 10 minutes.

4. Apply a partial vacuum to the contents for 10 minutes, to remove the entrapped air.

5. Stop the vacuum and carefully remove the vacuum line from pycnometer.

6. Fill the pycnometer with distilled water (to the mark), clean the exterior surface of the pycnometer with a clean, dry cloth. Record the weight of the pycnometer and contents, $\mathrm{W}_{\mathrm{s}}$.

7. Empty the pycnometer and clean it. Then fill it with distilled water only (only up to the mark). Clean the exterior surface of the pycnometer with a clean, dry cloth. Record the weight of the pycnometer and distilled water, $\mathrm{W}_{\mathrm{a}}$.

8. Empty the pycnometer and clean it.

\subsection{2: Fineness Modulus}

Procedure:

1. Weigh accurately $100 \mathrm{gm}$ of material and place it on a standard IS sieve 90 microns.

2. Breakdown any air set lumps in the sample with fingers but do not run on the sieve.

3. Continuously sieve the sample by holding the sieve in both hands and giving a gentle wrist motion or mechanical sieve shaker may be used for this purpose.

4. Weigh the residue left after 15 minutes sieving this residue shall not exceed the specified limits.

\subsection{3: Bulking Of Sand}

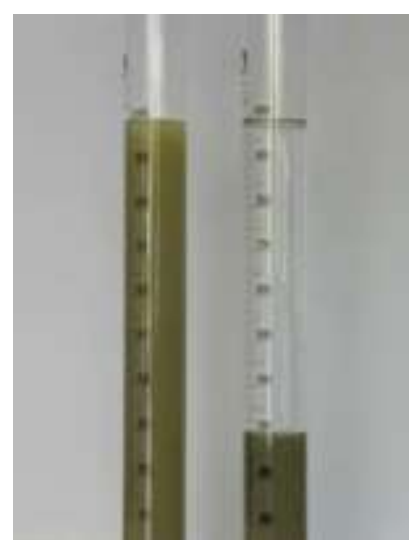

Fig 11: Measuring Jar with Graduations

Procedure:

1. Take $200 \mathrm{ml}$ of sand in measuring jar and take the weight of sand

2. Add water is one percentage of the weight (sand) and mixed thoroughly and measure the increasing volume.

3. Add 2\%, 3\%, 4\%....... and the process is repeated for number of times and each increase in volume is taken. 
4. After the increase in volume there is a slow decrease in volume, then pure water is added to the sand to increase it. That will give original volume.

5. When water is added the volume of sand increased and an optimum volume of sand reached.

\section{2.: Coarse Aggregate}

\subsection{1: Specific Gravity}

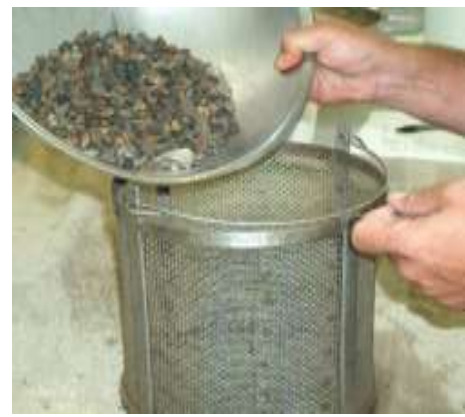

Procedure:

Fig 12: Mesh jar

1. About $2 \mathrm{~kg}$ of the aggregate sample is washed thoroughly to remove fines, drained and then placed in the wire basket and immersed in distilled water at a temperature between 22 to $32^{\circ} \mathrm{C}$ with a cover of at least $50 \mathrm{~mm}$ of water above the top of the basket.

2. Immediately after immersion the entrapped air is removed from the sample by lifting the basket containing it $25 \mathrm{~mm}$ above the base of the tank and allowing it to drop 25 times at the rate of about one drop per second. The basket and the aggregate should remain completely immersed in water for a period of $24+/-0.5$ hours afterwards.

3. The basket and the sample are then weighed while suspended in water at a temperature of $22^{\circ} \mathrm{C}$ to $32^{\circ} \mathrm{C}$. Weight is noticed while suspended in water $\mathrm{W}_{1} \mathrm{gm}$.

4. The basket and the aggregates are then removed from water and allowed to drain for a few minutes.

5. The empty basket is weighed in water $\mathrm{W}_{2}$.

6. The aggregates are dried till no further moisture could be removed.

7. The surface dried aggregate is then weighed $\mathrm{W}_{3} \mathrm{gm}$.

8. The aggregates are placed in an oven, cooled in an airtight container and weighed $\mathrm{W}_{4} \mathrm{gm}$.

\subsection{3: Fineness Modulus}

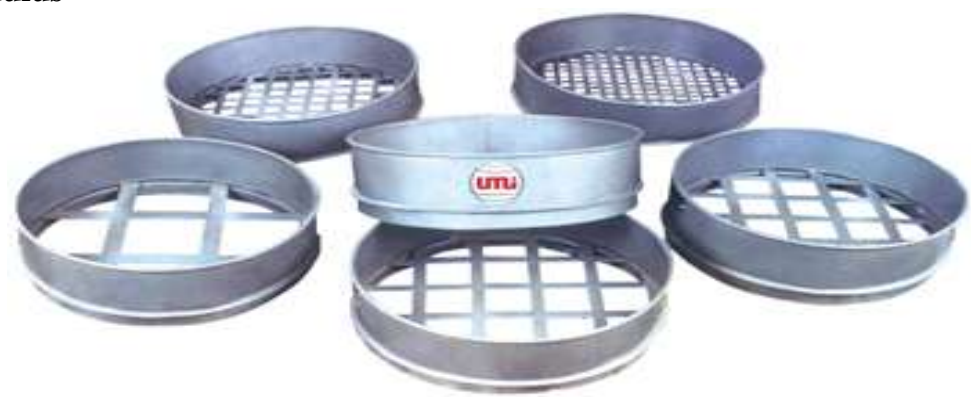

Fig 13:IS sieves

1. Take 5000 gm of coarse aggregate by weighing the material in a digital scale. Weigh each of the clean sieves, along with the bottom pan, and record their weights.

2. Place the aggregate in the sieves and sieve it.

3. Determine the aggregates that are retained in each individual sieve and record the data. To ensure that all materials are collected, use the steel brush to clean each sieve.

4. Tabulate the data and determine the percent retained, and the percentage that would have been retained in each sieve alone was used to sieve the whole volume. The fineness modulus is obtained by adding the percentage of material retained in all the sieves and dividing it by 100 .

5. Plot a graph of percent passing by weight vs. sieve sizes. 


\subsection{4: Impact Test}

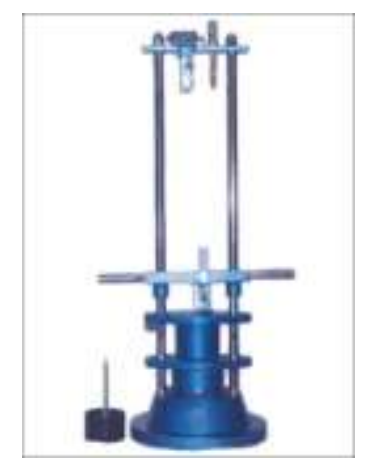

Procedure:

Fig 14: Impact testing machine

1. Sieve the materia through $12.5 \mathrm{~mm}$ and $10.0 \mathrm{~mm}$ IS sieve. The aggregate passing through $12.5 \mathrm{~mm}$ sieve and retained on $10.0 \mathrm{~mm}$ comprises the test material.

2. The cylinder of the test shall be put in position on the base plate and the test sample added in thirds, each third being subjected to 25 strokes with the tamping rod.

3. The surface of the aggregate shall be carefully levelled.

4. The plunger is inerted so that it rests horizontally on this surface, care being taken to ensure that the plunger does not jam in the cylinder.

5. The apparatus, with the test sample and plunger in position, shall then be placed between the plates of the testing machine.

6. The load is applied at the uniform rate as possible so that the load is reached in 10 minutes. The total load shall be 40 tonnes.

7. The load shall be released and the whole of the maaterial is removed from the cylinder and sieved on 2.36 mm IS sieve.

8. The fraction passing the sieve shall be weighed and recorded.

\section{3: Mix Design}

4.3.1: General

In these methods of mix design the IRC methods are not fit for the present work in which lower grades one of the ultimate aims of the various properties of the material of concrete is to enable the design of a concrete mix for a particular strength. Mix design can be defined as the process of selecting suitable ingredients of concrete and determining their relative properties with the object of producing concrete of certain minimum strength and durability as economically as possible.

These are various method of proportioning, to obtain the concrete mix.

These methods are as follows:

Arbitrary proportion method, Maximum density method, Fineness modulus method, Surface area method, ACI committee method, Grading curve method (road no.4), IRC-44 method, High strength concrete mix design, Indian standard mix design method

Out of the above method the first four are to very widely use these days due to inherent drawbacks in the procedures of mix adopted for arriving at satisfactory proportions. The procedure of mix design recommended by American concrete institute, IRC-road no: 4 and IS mix design are widely adopted.

Indian standard institutions have brought out the mix design procedure mainly based on the work done in national laboratories. This method can be applied to both medium strength and high strength concrete also. The various steps involved in mix design are given below:

\subsubsection{Indian Standard Mix Design}

The step by step procedure for the design mix by IS method is given below

Step 1: Target strength for the mix design

Target average mean compressive strength at 28 days is calculated using equation

$\mathrm{ft}=\mathrm{fck}+\mathrm{t} . \mathrm{s}$

$\mathrm{ft}=\mathrm{fck}+1.65 \times \mathrm{s}$

Where

$\mathrm{ft}=$ target mean strength of concrete at 28 days

$\mathrm{fck}=$ characteristics compressive strength of concrete at 28days

$\mathrm{t}=\mathrm{a}$ risk factor generally taken as $\mathbf{1 . 6 5}$

$\mathrm{s}=$ standard deviation for each grade of the concrete 
Step 2: selection of water cement ratio

(a)The free water ratio corresponding to the target strength may be determined from the graph between the compressive strength and water cement ratio.

(b)The free water cement ratio thus selected should be checked against the limiting water cement ratio for the durability requirement.

Step 3: Selection of water and sand content

After obtaining the water cement ratio,

(a)The percentage of sand and water content are obtained from the table as given in the IS code: 10262 -

82 , by knowing the maximum size of the coarse aggregate

(b)Necessary adjustment to the water cement ratio is to be done.

Step 4: Determination of cement content

After obtaining the water content and sand content,

(a)Cement content is determined using water cement ratio and water content. The equation,

Water content $=$ water content $/$ water - cement ratio

Step 5: Determination of coarse and fine aggregate

(a0) The fine aggregate is obtained using the equation

$V=[W+(C / S c)+(F a / S f a * p)] *(1 / 1000)$

(b) The coarse aggregates using the equation

$C a=\{(1-p) / p\} * F a *(S c a / S f a)$

$\mathrm{V}=\mathrm{absolute}$ volume of fresh concrete which is equal to gross volume (in cum)

minus volume of entrapped air.

$\mathrm{W}=$ mass of water $(\mathrm{kg})$ per cum of concrete

$\mathrm{C}=$ mass of cement $(\mathrm{kg})$ per cum of concrete

$\mathrm{Sc}=$ specific gravity of cement

$\mathrm{P}=$ ratio of fine aggregate to total aggregate by absolute volume

$\mathrm{Fa}, \mathrm{Ca}=$ total masses of $\mathrm{FA}$ and $\mathrm{CA}(\mathrm{kg})$ per cum of concrete respectively

$\mathrm{Sfa}, \mathrm{Sca}=$ specific gravities of saturated, surface fine aggregate and coarse aggregate respectively.

After obtaining the fine aggregate and coarse aggregate contents, the mix design (ratio) is finalised by certain trials by examining the results, ratios are adopted. The mixed design for M20 is illustrated below:

M20 MIX DESIGN

Design stipulations:

Characteristics compressive strength required in

The field at 28days

Maximum size of aggregate

$20 \mathrm{~N} / \mathrm{mm} 2$

Degree of workability

$20 \mathrm{~mm}$

Degree of quality control

0.85 comp. factor

Type of exposure

Good

Test Data for Exposure:

Gypsum used - phospogypsum

Satisfying the requirement of IS: 10262

\begin{tabular}{|c|c|c|c|l|}
\hline Sample no. & Gypsum & Fly Ash & Lime & Specific Gravity \\
\hline 1 & 80 & 10 & 10 & 1.50 \\
\hline 2 & 70 & 10 & 20 & 1.80 \\
\hline 3 & 60 & 10 & 30 & 1.08 \\
\hline 4 & 60 & 20 & 20 & 1.43 \\
\hline
\end{tabular}

Table 4: Specific gravity of proportions

Specific gravity of Coarse aggregate $=2.72$

Specific gravity of fine aggregate $=2.60$

Target mean strength of concrete

$f t=f c k+t * s$

For a tolerance factor $(\mathrm{t})=1.65$

And according to Table of IS: 10262-1982, Standard deviation (s) $=4.6$

$f t 1=20+1.65 * 4.6=27.6 \mathrm{~N} / \mathrm{mm} 2$

$$
f t 2=20+1.65 * 4.6=27.6 \mathrm{~N} / \mathrm{mm} 2
$$

$f t 3=20+1.65 * 4.6=27.6 \mathrm{~N} / \mathrm{mm} 2$

$f t 4=20+1.65 * 4.6=27.6 \mathrm{~N} / \mathrm{mm} 2$

Selection of water-cement ratio: 
From fig 1 of IS: 10262 the free water cement ratio required for the target mean strength of $27.6 \mathrm{~N} / \mathrm{s}-$ $\mathrm{m}$ is 0.5 . This is lower than the maximum value of 0.65 prescribed for mild exposure in Appendix

A of IS: 456:2000.

Selection of water content:

From table 4 of IS : 10262, for 20mm maximum size aggregate and sand conforming to zone 2 , water content per cubic meter of concrete $=186 \mathrm{~kg}$

Sand content as percentage of total aggregate $=35 \%$

After adjustments, required water content $=186$ lit

Required percentage of sand as $\%$ of total aggregate $=35-3.5=31.5 \%$

Determination of Binding material content:

Binding material content $=186 / 0.50=372 \mathrm{~kg} / \mathrm{m} 3$

Determination of coarse and fine aggregate content:

From table 3 of IS: 10262 and for 20mm maximum size aggregate, the amount of entrapped air is $2 \%$.

Mass of fine aggregate is obtained from the relation

$V=[W+(C / S c)+(1 / \rho) *(F a / S f a)] *(1 / 1000)$

1. $0.98=(186+(372 / 1.50)+(1 / 0.315) *(F a / 2.60) *(1 / 1000)$

Therefore mass of fine aggregate per one cubic meter of concrete, $F_{1}=447.174 \mathrm{~kg}$.

2. $0.98=(186+(372 / 1.80)+(1 / 0.315) *(F a / 2.60) *(1 / 1000)$

Therefore mass of fine aggregate per one cubic meter of concrete, $\mathrm{FA}_{2}=481.026 \mathrm{~kg}$

3. $0.98=(186+(372 / 1.08)+(1 / 0.315) *(F a / 2.60) *(1 / 1000)$

Therefore mass of fine aggregate per one cubic meter of concrete, $\mathrm{FA}_{3}=368.186 \mathrm{~kg}$

4. $0.98=(186+(372 / 1.43)+(1 / 0.315) *(F a / 2.60) *(1 / 1000)$

Therefore mass of fine aggregate per one cubic meter of concrete, $\mathrm{FA}_{4}=438.71 \mathrm{~kg}$.

Mass of coarse aggregate is obtained from the relation

$$
V=[W+(C / S c)+(1 / 1-\rho) *(C a / S c a)] *(1 / 1000)
$$

1. $0.98=[186+(372 / 1.50)+(1 / 1-0.315) *(C a / 2.72)] *(1 / 1000)$

Therefore mass of fine aggregate per one cubic meter of concrete, CA1 $=1017.30 \mathrm{~kg}$.

2. $0.98=[186+(372 / 1.80)+(1 / 1-0.315) *(C a / 2.72)] *(1 / 1000)$

Therefore mass of fine aggregate per one cubic meter of concrete, $\mathrm{CA}_{2}=1094.31 \mathrm{~kg}$.

3. $0.98=[186+(372 / 1.08)+(1 / 1-0.315) *(C a / 2.72)] *(1 / 1000)$

Therefore mass of fine aggregate per one cubic meter of concrete, $\mathrm{CA}_{3}=837.61 \mathrm{~kg}$.

4. $0.98=[186+(372 / 1.43)+(1 / 1-0.315) *(C a / 2.72)] *(1 / 1000)$

Therefore mass of fine aggregate per one cubic meter of concrete, $\mathrm{CA}_{4}=998.05 \mathrm{~kg}$. PROPORTIONS OF WATER, BM, FA \& CA:

For sample 1:

\begin{tabular}{|c|c|c|c|}
\hline Water & Binding material & Fine aggregate & Coarse aggregate \\
\hline 186 & 372 & 447.174 & 1017.30 \\
\hline 0.5 & 1 & 1.2 & 2.73 \\
\hline
\end{tabular}

For sample 2:

For sample 3

\begin{tabular}{|c|c|c|c|}
\hline Water & Binding material & Fine aggregate & Coarse aggregate \\
\hline 186 & 372 & 481.026 & 1094.31 \\
\hline 0.5 & 1 & 1.29 & 2.94 \\
\hline
\end{tabular}

\begin{tabular}{|c|c|c|c|}
\hline Water & Binding material & Fine aggregate & Coarse aggregate \\
\hline 186 & 372 & 368.186 & 837.61 \\
\hline 0.5 & 1 & 0.98 & 2.25 \\
\hline
\end{tabular}

For sample 4:

\begin{tabular}{|c|c|c|c|}
\hline Water & Binding material & Fine aggregate & Coarse aggregate \\
\hline 186 & 372 & 438.71 & 998.05 \\
\hline 0.5 & 1 & 1.17 & 2.68 \\
\hline
\end{tabular}

Quantity of concrete required for 3 cubes and 3 cylinders.

Volume of each cube $=0.15 \times 0.15 \times 0.15$

$$
=0.003375 \mathrm{cum}
$$




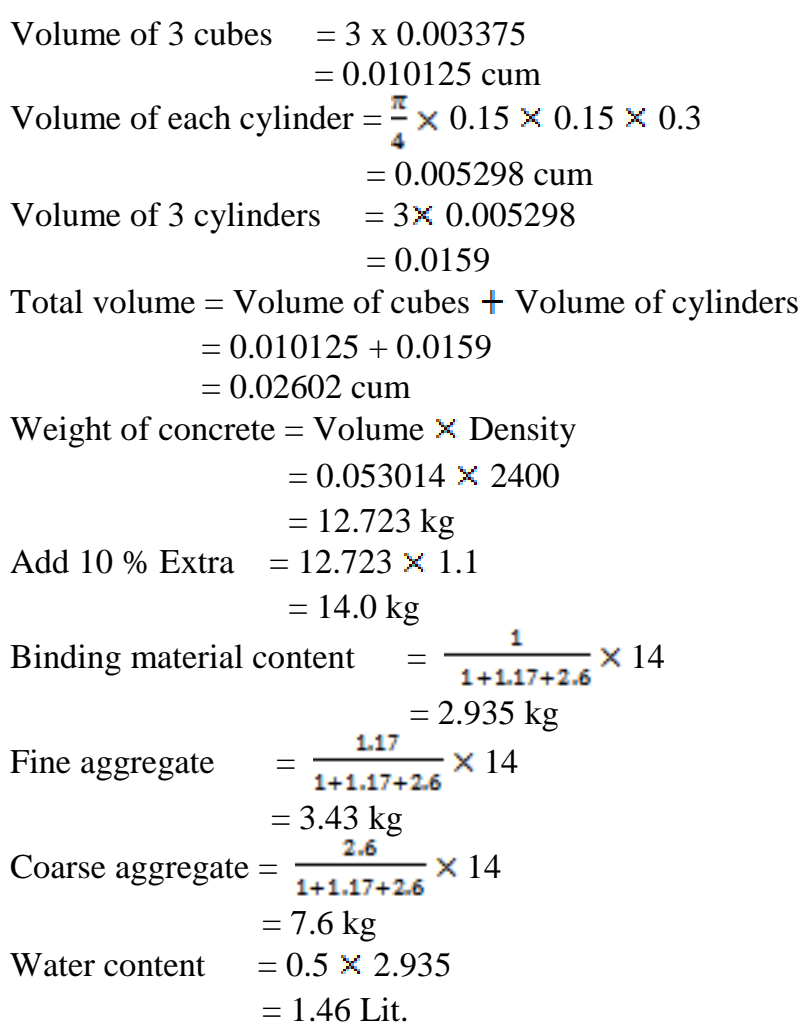

\section{1: Casting}

\section{EXPERIMENTAL PROGRAMME}

\subsection{1: Cubes}

The sizes of cube specimen are $150 \mathrm{~mm} \times 150 \mathrm{~mm} \times 150 \mathrm{~mm}$. The moulds for the casting of specimens were made of cast

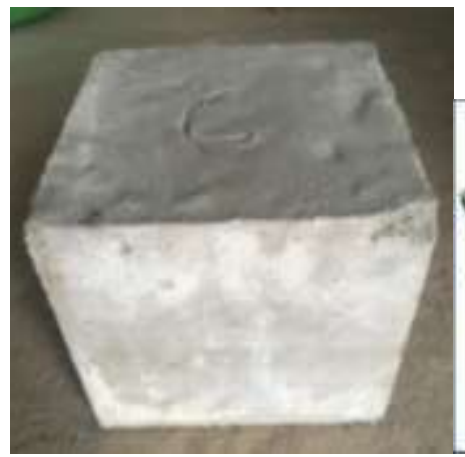

CUBE

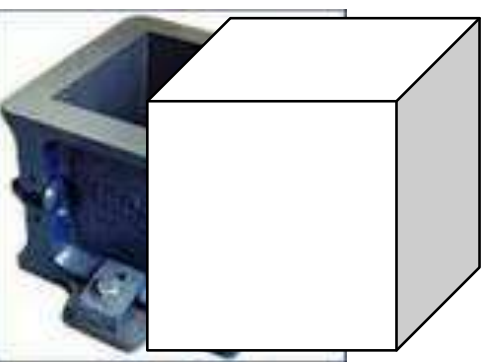

\section{CUBE MOULD}

\subsection{2: Cylinders}

The sizes of cylinder specimens are $150 \mathrm{~mm}$ in diameter and $300 \mathrm{~mm}$ height. The above specimens were made of cast iron material of same size.

$300 \mathrm{~mm}$

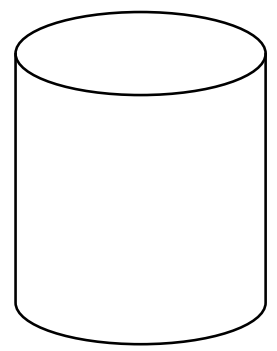



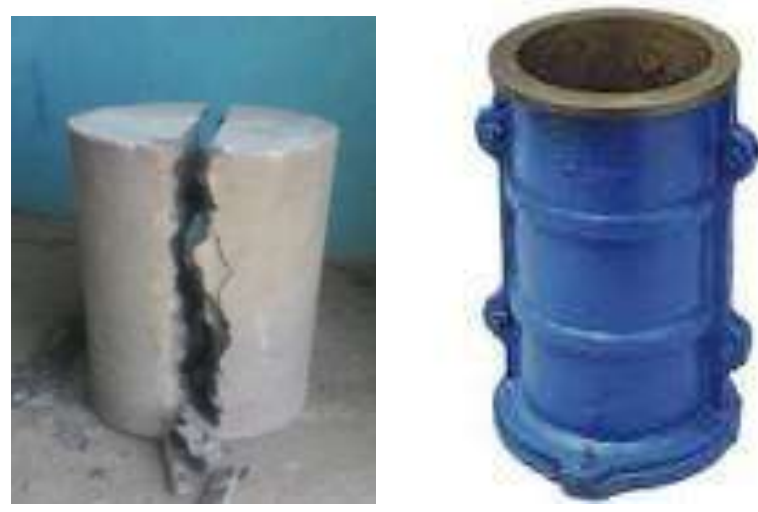

CYLINDER MOULD

\section{TESTED CYLINDER}

\subsection{Testing Procedure}

\subsection{1: Compaction}

Compaction was done by hand using the standard tamping rod and the stokes of the rod were uniformly distributed over the cross section of mould. The concrete was filled in 3 layers and for each layer 25 strokes are applied.

\subsection{2: Casting}

Four different mixes were employed to examine the influence of adding fibres in concrete.

The moulds used for casting were oiled and four sides of the moulds and screws were tightened well. The fresh concrete was smoothly transferred into mould into three stages and compacted with the help of tamping rod. After casting the top surface of the mould is leveled using the trowel. The specimens are demoulded after $24 \mathrm{hrs}$ of casting.

The designations oil specimens are marked with indelible waterproof ink and kept under water under curing.

\subsection{3: Curing}

Temperature conditions for freshly placed concrete for some specified time for proper hardening of concrete.

The specimens were cured for 28 days in curing pond. After the completion of the period, the specimens were removed from the water and kept under shadow for specimen to get surface dry condition.

\subsection{4: Testing}

After drying of specimens for 24hours under the shadow were tested for strength parameters as discussed below.

\subsubsection{1: Compressive Strength}

The cube specimens are tested on compressive testing machine of 200 tones and the machine was operated hydraulically. The bearing surface of testing machine wiped of clean and loss sand or other materials removed from the surface of the specimen are in machine in such manner the loads were applied to the opposite side of the cubes as tested that is, not to the top and bottom. The axis of specimen was carefully aligned with the center of the thrust of the spherical scatted plate. The load was applied without shock and increased continuously at a rate of approximately $140 \mathrm{~kg} / \mathrm{sq} . \mathrm{cm} / \mathrm{min}$ until the resistance of the specimen to the increasing load breakdown and the no greater load can be sustained. The maximum load applied to the specimen was recorded.

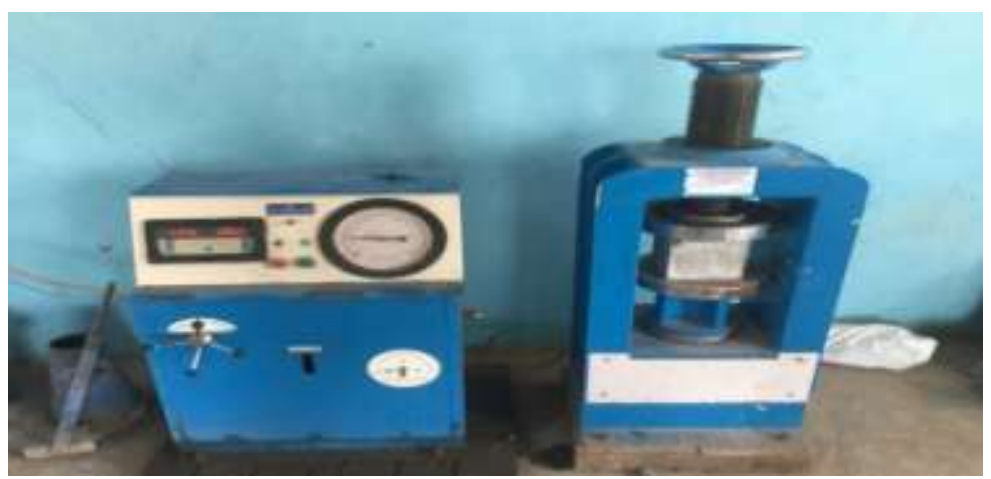

Fig 15: CTM

Procedure:

1) Remove the specimen from water after specified curing time and wipe out excess water from the surface.

2) Take the dimensions of the specimen.

3) Clean the bearing surface of the testing machine. 
4) Place the specimen in the machine in such a manner that the load shall be applied to the opposite sides of the cube cast.

5) Align the specimen centrally on the base plate of the machine.

6) Rotate the movable portion gently by hand so that it touches the top surface of the specimen.

7) Apply the load gradually without shock and continuously till the specimen fails.

8) Record the maximum load and note any used features in the type of failure ( Load may be applied at the rate of rate of $140 \mathrm{~kg} / \mathrm{cm}$.

$$
\text { Compressive strength }=\mathrm{L} / \mathrm{A} \text { in } \mathrm{N} / \mathrm{mm}^{2}
$$

\subsubsection{2: Split Tensile Strength}

The tensile strength is one of the basic and important properties of the concrete. The concrete is not usually expected to resist the direct tension because of its low tensile strength and brittle nature. However, the determination of tensile strength of concrete is necessary to determine the load at which the concrete members may crack. The cracking is a form of tension failure.In these tests in general a compressive force is applied to a concrete specimen in such a way that the specimen fails due to tensile stresses developed in the specimen. The tensile stress at which the failure occurs is termed the tensile strength of concrete.

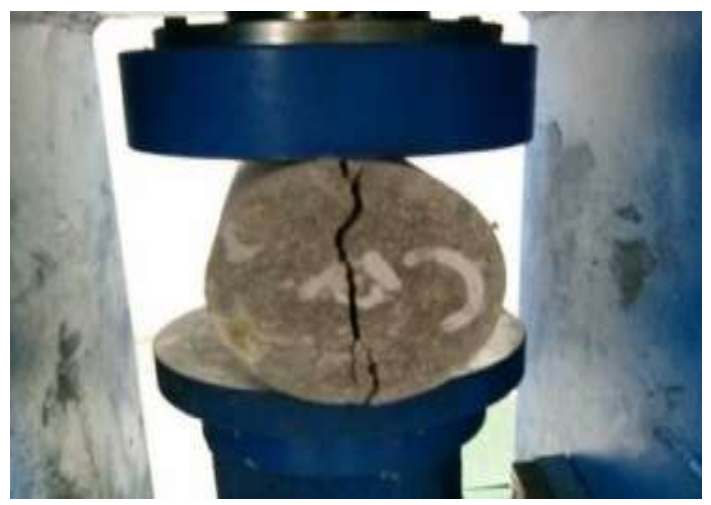

Fig 16: Split tensile testing

Procedure:

1) Take the wet specimen from water after specified time and wipe out excess water from the surface.

2) Draw the diametrical lines on the two ends of the specimen to ensure that they are on the axial place.

3) Note the weight and diameter of the specimen.

4) Set the compression testing machine for the required range.

5) Keep the plywood strip on the lower place and place the specimen.

6) Align the specimen so that the lines marked on the ends are vertical and centered over the bottom plate.

7) Place the other plywood strip above the specimen.

8) Bring down the upper plate to touch the plywood strip.

9) Apply the load continuously without a stock at a rate of approximately $14-21 \mathrm{~kg} / \mathrm{cm} 2$ per minute.

10) Note down the breaking load (P).

Split tensile strength, $\mathrm{T}=2 \mathrm{P} \pi \mathrm{DL}$.

\section{Compressive Strength}

\section{RESULTS AND DISCUSSIONS}

The cubes compressive strength for all the mixes at 28 days with and without addition of fibers is presented in the table below.

\section{Splitting Tensile Strength}

The cubes splitting tensile strength for all the mixes at 28days with and without addition of fibers are presented in the table below.

\begin{tabular}{|l|l|l|l|l|}
\hline Description & $\begin{array}{l}\text { Compressive } \\
\text { Strength }\end{array}$ & $\begin{array}{l}\text { Compressive } \\
\text { Strength }\end{array}$ & $\begin{array}{l}\text { SplitTensile } \\
\text { Strength }\end{array}$ & SplitTensile Strength \\
\hline Cement & Without Fibres & $\begin{array}{l}\text { With } \\
\text { Fibres }\end{array}$ & $\begin{array}{l}\text { Without } \\
\text { Fibres }\end{array}$ & $\begin{array}{l}\text { With } \\
\text { Fibres }\end{array}$ \\
\hline & 18 & 25 & 7 & 12 \\
\hline
\end{tabular}

\begin{tabular}{|l|l|l|l|l|}
\hline Description & $\begin{array}{l}\text { Compressive } \\
\text { Strength }\end{array}$ & $\begin{array}{l}\text { Compressive } \\
\text { Strength }\end{array}$ & $\begin{array}{l}\text { SplitTensile } \\
\text { Strength }\end{array}$ & SplitTensile Strength \\
\hline Sample & Without Fibres & With & Without & With \\
\hline
\end{tabular}




\begin{tabular}{|l|l|l|l|l|}
\hline number & & Fibres & Fibres & Fibres \\
\hline Sample1 & 6 & 10 & 1 & 3 \\
\hline Sample2 & 8 & 12 & 2 & 4 \\
\hline Sample3 & 9 & 13 & 3 & 5 \\
\hline Sample4 & 10 & 16 & 5 & 7 \\
\hline
\end{tabular}

\section{CONCLUSION AND FUTURE SCOPE}

It is observed that as the lime content increasing the strength is also increasing but amount of increase in strength from $5 \%$ to $10 \%$ is more and from $10 \%$ to $15 \%$ is less. Addition of lime in excess to fly ash may not be beneficial. As the curing period increases the strength also increases. But increase in strength from 7 days to 14 days curing is more than from 14 days to 21 days curing. Up to certain days of curing there will be no more increase in strength.Based upon data recorded, it can be concluded that specimen containing fly ash with appropriate proportion of certain additives can be proportioned to meet the strength and workability requirement for structural grade concretes and Geotechnical application.After conducting all the experiments related to strength development of fly ash based composite materials the following are the factors that affect Strength Gain of Lime- -Fly ash composite material:

- Fly ash type (classification, particle size and distribution, etc.)

- Types of stabilization agent/agents

- Preparation of sample

- Sample size (mould size)

- Curing time

\section{FUTURE SCOPE OF STUDY:}

Due to self-hardening properties of fly ash they have wide spread application. If more number of samples could have been taken and more days curing period have been taken then it could have given more accurate results. From the above analysis of samples \& based on the results obtained, it can be suggested that the Strength of the fly ash composite materials can be further increased by adding the necessary additives in a higher percentage amount \& providing them enough curing period for better compaction. For which those composites can fulfil the requirements for construction purposes

\section{REFERENCES}

[1] Dhir, R.K. (2005): Emerging trends in fly ash utilization: World Scenario, Proc. Of International Conference on fly ash utilization, pp: O 1.1-1.10.

[2] Sen, S. and Kumar, A. (1995): NTPC's experience in utilization of coal ash, Proc. of the Workshop on fly ash Utilization, pp: 103 121.

[3] Kumar, V. (2006): Fly ash: A resource for sustainable development, Proc. of the International Coal Congress \& Expo, 191-199.

[4] Helmath R. (1987): Fly Ash in Cement and Concrete, Portland cements Association, Research and Development Laboratories, Skokie, IL.

[5] Yudhbir, and Honjo, Y. (1991): Application of Geotechnical Engineering to Environmental Control, Theme lecture 5, 9 ARC Bangkok, Thailand, Vol.2, 431-469.

[6] Pandian, N.S. (2004): "Fly Ash Characterization with reference to Geotechnical Applications", Journal of Indian Institute of Science, Vol. (84), 189-216.

[7] Sivapullaiah (1995): Optimization of Lime Content for Fly Ash, Journal of Testing and Evaluation, JTEVA, Vol.23, No.3, pp: 222227.

[8] Bumjoo, K., Monica, P. and Rodrigo, S. (2005): "Geotechnical Properties of Fly and Bottom Ash Mixtures for Use in Highway Embankments", Journal of Geotechnical and Geo-environmental Engineering @ $)$ ASCE, pp: 914-924.

[9] Sahu, K.C. (1991): "Coal and fly ash problem”, Proc.Intl. Conf. on Environmental impact of coal utilization from raw materials to waste resources (K.C. Sahu, ed.), Indian Institute of Technology, Bombay, pp: 11-12.

[10] Pandian, N.S. and Balasubramonian, S. (1999): "Permeability and consolidation behavior of fly ashes", Journal of Testing and Evaluation, JTEVA, Vol. (27), No.5, 337-342.

[11] Murty, A.V.S.R. (1996): "Fly Ash in construction of roads and embankments", Ash ponds and Disposal Systems (V.S.Raju et al., Eds), Narosa publishing House, New Delhi, 222-37.

[12] Prashant (2005): "Use of coal ash in Open Cast mine filling", National Seminar cum business meet on use of Fly Ash in mining sector, pp: $34-39$. 